\title{
Controlled behavioural experiments
}

Therese Lindahl, 1,2 Marco A. Janssen ${ }^{3}$ and Caroline Schill, ${ }^{1,2}$

${ }^{1}$ BEIJER INSTITUTE OF ECOLOGICAL ECONOMICS, THE ROYAL SWEDISH ACADEMY OF SCIENCES, STOCKHOLM, SWEDEN

${ }^{2}$ STOCKHOLM RESILIENCE CENTRE, STOCKHOLM UNIVERSITY, STOCKHOLM, SWEDEN

${ }^{3}$ SCHOOL OF SUSTAINABILITY, AND SCHOOL OF COMPLEX ADAPTIVE SYSTEMS, ARIZONA STATE UNIVERSITY,

TEMPE, ARIZONA, USA

\section{Key methods discussed in this chapter}

Controlled behavioural experiments

\section{Connections to other chapters}

Some sort of statistical analysis (Chapter 18) is needed and used to analyse the experimental data obtained from controlled behavioural experiments. Interviews or surveys (Chapter 7) are often conducted in combination with the experiment to collect relevant data on potential drivers and motivations for the observed behaviour. More recently, these experiments have also been used in combination with agent-based modelling (Chapter 28) to develop and test different mechanisms that can explain observed outcomes. Finally, the game designs of these experiments can also be set up as role-playing serious games (Chapter 12) and some researchers also use them in the classroom as a pedagogical tool.

\section{Introduction}

Many sustainability challenges confronting us are associated with some sort of collective action problem: while a group benefits from joint action, no one has the incentive to take that action individually. We would all enjoy the benefits from investments made to reduce greenhouse gas emissions, for example, but progress is remarkably slow because it is not in the individual countries' interest to halt emissions on their own. Likewise, a group of fishers with access to the same fishing ground would benefit from individual efforts to reduce overfishing, but each fisher would be better off by catching as many fish as possible. If everybody acts only in their self-interest, the aggregate outcome can be disastrous for both people and ecosystems. Solving these collective action problems is challenging and has preoccupied scholars from various disciplines for decades (see Ostrom 1990; Bromley 1992; Barrett 2016). 


\section{SUMMARY TABLE: CONTROLLED BEHAVIOURAL EXPERIMENTS}

\begin{tabular}{|c|c|}
\hline DISCIPLINARY BACKGROUND & KNOWLEDGE TYPE \\
\hline $\begin{array}{l}\text { The methods in this chapter are derived } \\
\text { from or have most commonly been used in: } \\
\text { Experimental and Behavioural } \\
\text { Economics, Social and Cognitive } \\
\text { Psychology, Environmental and } \\
\text { Cultural Psychology }\end{array}$ & $\begin{array}{l}\text { The methods in this chapter are primarily } \\
\text { used to generate the following types of } \\
\text { knowledge: } \\
\text { - Explanatory }\end{array}$ \\
\hline RESEARCH APPROACH & PURPOSE OF METHOD \\
\hline $\begin{array}{l}\text { The methods in this chapter originate } \\
\text { from or most commonly adopt the } \\
\text { following research approaches: } \\
\text { - Analytical/objective }\end{array}$ & $\begin{array}{l}\text { The most common purposes of using the } \\
\text { methods in this chapter are: } \\
\text { - Data collection/generation } \\
\text { - System understanding }\end{array}$ \\
\hline TEMPORAL DIMENSION & SYSTEMIC FEATURES AND PROCESSES \\
\hline $\begin{array}{l}\text { The methods in this chapter are most } \\
\text { commonly applied to the following } \\
\text { temporal dimensions: } \\
\text { - Present (typically within the last } \\
5-10 \text { years) }\end{array}$ & \multirow{3}{*}{$\begin{array}{l}\text { While most methods can do many } \\
\text { things, the methods in this chapter are } \\
\text { particularly good (i.e. go-to methods) for } \\
\text { addressing the following: } \\
\text { - Social-ecological interactions } \\
\text { over time } \\
\text { - Adaptation and self-organisation } \\
\text { - Collective action and collaborative } \\
\text { governance }\end{array}$} \\
\hline SPATIAL DIMENSION & \\
\hline $\begin{array}{l}\text { The methods in this chapter are primarily } \\
\text { either or both: } \\
\text { - Non-spatial } \\
\text { The methods in this chapter are most } \\
\text { commonly applied at the following } \\
\text { spatial scales: } \\
\text { - Local } \\
\text { - Multiple places/sites around the world }\end{array}$ & \\
\hline
\end{tabular}


This chapter focuses on two types of controlled behavioural experiments designed to study collective action in social-ecological systems (SES): so-called public good and common-pool resource game experiments (Janssen, Lindahl, and Murphy 2015). In both types of games, each individual can either take an action that would benefit the entire group or choose an action that would maximise individual returns. In a public good game, the individual decides whether or not to invest in a public good, e.g. an irrigation system or pollution mitigation. In a common-pool resource game, the individual decides how much to extract from a common-pool resource, e.g. how much to fish from a shared fishing ground or how much timber to harvest from a forest.

Controlled experiments are grounded in a positivist perspective, which emphasises empirical evidence with the intent to uncover 'objective' patterns and regularities. These experiments have been, and still are, a widely used methodology in the natural sciences. Over the past few decades, the experimental methodology has been increasingly adopted by social scientists, especially in economics and psychology, as it enables the researcher to explore and test hypotheses about human behaviour when people face different situations (Falk and Heckman 2009). Participants are randomly assigned to different groups (called 'treatments') so that the only difference between these groups is the variable of interest. In this sense, the researcher 'controls' these different situations. By virtue of this control, experiments allow the researcher to establish a causal link between the observed behaviour and the variable of interest.

The experimental methods discussed in this chapter mainly follow the experimental economics tradition (Smith 1976). This tradition emphasises the importance of providing participants with sufficient incentives (often, but not necessarily, monetary) in order to make participants act as they would in a real situation. Moreover, this compensation should be directly linked to decisions taken to avoid a potential hypothetical bias, e.g. in the form of behaving more (or less) cooperatively because decisions have no monetary consequence. Also, unlike psychological experiments, economic experiments do not allow for the deception of participants. Whereas economists design experiments mainly to analyse market outcomes, psychologists (and later behavioural economists) are predominantly interested in individual behaviour. This chapter aligns more with the general interest in human behaviour that guides psychologists (and later behavioural economists) than with experiments designed by traditional experimental economists to analyse market outcomes.

The controlled behavioural experiments discussed in this chapter are particularly suitable for studying collective action in SES because they allow the experimenter to mimic key social-ecological interactions and interdependencies over time. Each action an individual takes in the experiment affects the shared resource (public good or common-pool resource), which in turn affects the individuals' returns (i.e. their livelihoods in reality).

\section{SES problems and questions}

The overall purpose of using controlled experiments in the form of public good and commonpool resource games is to test under what conditions we can expect collective action to emerge, i.e. resource users to cooperate (or not) around shared resources, and by extension to attain sustainable resource use. Since the first public good experiments (Dawes, McTavish, and Shaklee 1977) and the first common-pool resource experiments (Jorgenson and Papciak 1981; Ostrom, Walker, and Gardner 1992) were undertaken, a huge number of variants and 
extensions of both these types of experiments have been performed. Experiments have been designed to answer research questions such as:

- What is the role of communication and costly sanctioning for achieving successful cooperation around shared resources? (e.g. see Ostrom, Walker, and Gardner 1992; Cárdenas 2000; Ostrom 2006 for a review)

- Are larger groups less likely to form cooperative agreements around shared resources than smaller groups? (e.g. see Kerr 1989; Pereda, Capraro, and Sanchez 2019)

- What motives are important for sustaining cooperation around shared resources? (e.g. see Ostrom 2000; Fehr and Fischbacher 2002; Kopelman, Weber, and Messick 2002; Cárdenas and Ostrom 2004; Velez, Strandlund, and Murphy 2009 for reviews)

- What is the effect of different institutions (such as an externally imposed regulation) on cooperation around shared resources? (e.g. see Cárdenas, Strandlund, and Willis 2000; Vollan 2008; Moreno-Sánchez and Maldonado 2010; Lopez et al. 2012)

Most public good and common-pool resource experiments to date (including the listed examples above) focus on social interactions and dynamics (the different social conditions are represented by different treatments, e.g. comparing outcomes where groups are allowed to communicate to outcomes where groups are not allowed to communicate). These experiments do not include some of the important challenges experienced by resource users associated with natural resource dynamics (notable exceptions include Walker and Gardner 1992; Herr, Gardner, and Walker 1997).

In recent years, a 'new generation' of public good and common-pool resource experiments has emerged (Cárdenas, Janssen, and Bousquet 2013). In this new generation of experiments, which are especially relevant for SES research, there is specific emphasis on including relevant ecological features and dynamics, such as thresholds and regime shifts, spatial heterogeneity, asymmetrical resource access and past ecological conditions. The overall purpose of using the 'new generation' of public good and common-pool resource experiments is still to test under what conditions we can expect relative changes in the level of cooperation, or when cooperation emerges (or not). What separates these new experiments from previous experiments is primarily the specific experimental context, which may also be represented in the treatments themselves. In a nutshell, the different treatments can represent different social conditions in a specific ecological context, or different ecological conditions in a specific social context. These experiments have been designed to answer questions such as:

- What is the role of communication and punishment in a common-pool resource setting with spatial and temporal stochastic resource dynamics? (e.g. see Janssen et al. 2010)

- How will asymmetrical resource access influence users' willingness to invest in shared infrastructure for shared resource provision? (e.g. see Janssen, Anderies, and Cárdenas 2011; Anderies et al. 2013)

- What is the role of potential ecological regime shifts (driven by resource users' own actions) for cooperation and resource use? (e.g. see Schill, Lindahl, and Crépin 2015; Lindahl, Crépin, and Schill 2016; Lindahl and Jarungrattanapong 2018; Schill and Rocha 2019; also see Case study 21.1 for more details)

- How will global, externally driven uncertainties about future resource flows influence behavioural strategies of local resource users? (e.g. see Cárdenas et al. 2017; Finkbeiner et al. 2018) 
- What is the impact of culture and past ecological constraints on cooperation concerning shared resources? (e.g. see Prediger, Vollan, and Frölich 2011; Gneezy, Leibbrandt, and List 2015)

\section{Brief description of key methods}

This chapter discusses different types of game designs (public good and common-pool resource) (Table 21.1). These game designs can in turn be implemented with different types of experiments. A laboratory (lab) experiment is, for example, performed with students as participants and often with neutral instructions, speaking about the other participants, costs and benefits, choice options A or B, among other things. A framed lab experiment also uses students as participants, but here the researcher uses instructions containing context-specific elements (e.g. letting participants know that they represent fictive resource users such as fishers and that they, together with other fictive fishers, have access to a common fishing ground). Framed instructions are common in public good and common-pool resource game experiments as it can be hard for a researcher to inform participants of certain resource

Table 21.1 Summary of key applications of controlled behavioural experiments

\begin{tabular}{|c|c|c|}
\hline Main applications & Description & References \\
\hline $\begin{array}{l}\text { Public good } \\
\text { experiment }\end{array}$ & $\begin{array}{l}\text { Each participant decides in each round how } \\
\text { much to contribute to a public good that is } \\
\text { shared by the group. The socially preferred } \\
\text { outcome is that everyone contributes. But } \\
\text { from the individual's perspective, the rational } \\
\text { egoistic choice is to contribute zero (in finite } \\
\text { games). }\end{array}$ & $\begin{array}{l}\text { Applications to SES in the lab } \\
\text { Barrett and Dannenberg } 2012 \\
\text { Applications to SES in the field } \\
\text { Cárdenas et al. } 2017\end{array}$ \\
\hline $\begin{array}{l}\text { Common-pool } \\
\text { resource investment } \\
\text { experiment }\end{array}$ & $\begin{array}{l}\text { Each participant decides in each round } \\
\text { how much to invest in two types of goods } \\
\text { (or markets), where one of the goods is a } \\
\text { common-pool resource and the other a } \\
\text { private good. Investment in the common- } \\
\text { pool resource (such as allocating time to } \\
\text { harvesting from the common-pool resource) } \\
\text { means more exploitive behaviour. The } \\
\text { socially preferred outcome is associated with } \\
\text { more moderate investments in the common- } \\
\text { pool resource compared to the individually } \\
\text { preferred choice based on a rational egoistic } \\
\text { decision-maker (in finite games). }\end{array}$ & $\begin{array}{l}\text { Applications to SES in the lab } \\
\text { Ostrom } 2006 \\
\text { Applications to SES in the field } \\
\text { Cárdenas } 2000\end{array}$ \\
\hline $\begin{array}{l}\text { Common-pool } \\
\text { resource extraction } \\
\text { experiment }\end{array}$ & $\begin{array}{l}\text { Each participant decides in each round } \\
\text { how much of the common-pool resource } \\
\text { to extract. The socially preferred outcome } \\
\text { is associated with less extraction of the } \\
\text { common-pool resource compared to the } \\
\text { individually preferred choice based on a } \\
\text { rational egoistic decision-maker (in finite } \\
\text { games). }\end{array}$ & $\begin{array}{l}\text { Applications to SES in the lab } \\
\text { Hine and Gifford } 1996 \\
\text { Applications to SES in the field } \\
\text { Gelcich et al. } 2013\end{array}$ \\
\hline
\end{tabular}


dynamics or other ecological conditions without mentioning natural resources or ecosystem dynamics. The researcher can also take the lab design to the field and analyse the behaviour of non-students (e.g. resource users), in which case we talk about field experiments. Again, if the instructions contain specific contextual elements, we talk about a framed field experiment (see Harrison and List 2004 for an overview of different types of experiments). Most common-pool resource and public good experiments relevant for social-ecological research are either framed lab experiments or framed field experiments.

The choice of the type of game and experiment is at the discretion of the researcher and will depend on the research question. However, it is not uncommon for the researcher to use several types of games and experiments, e.g. evaluating a design in the lab before taking it to the field. Regardless of type, the experimental implementation of these games typically involves four to eight participants. Over a number of rounds, which can be one or several (known or unknown to the participants), each participant makes a private and anonymous decision about how much to contribute to the provision of a public good or to appropriate/ extract from a common-pool resource. Table 21.1 provides some examples of different types of experiments (lab and field) applied to the different games (public good and common-pool resource).

Public good and common-pool resource experiments are often complemented by one or several other standardised controlled behavioural experiments. Eliciting preferences towards risk or uncertainty, for example, often involves a design where participants are asked to make a choice between different lotteries that are more or less risky (see e.g. Cárdenas and Carpenter 2009). Altruistic tendencies are typically measured through the dictator game (see Engel 2011 for a review). The willingness to invest in trust and the willingness to reciprocate trust are often measured through the trust game (see Johnson and Mislin 2011 for a review).

Besides analysing collective action problems and eliciting risk preferences or social preferences, controlled behavioural experiments are also valuable when evaluating different types of interventions (e.g. policies), where the different interventions represent the different treatments. Experiments of this nature that use citizens or consumers (non-students) as participants without them knowing they are participating in an experiment are called natural field experiments or randomised control trials (see Harrison and List 2004 for more details).

\section{Limitations}

With a controlled experiment it is only possible to test the effect of one variable at a time, which can be a limitation if the researcher wants to study different aspects of a complex system. Experimental programmes can be set up to test several variables and their interactions, but that requires substantial resources. Performing quantitative statistical analysis requires large enough sample sizes and collecting experimental data is costly and time consuming. Also, in the field it can be difficult to get enough participants, especially because of potential 'contamination' effects in smaller communities. An experimenter cannot stay too long in the same community because community members will talk to one another and share experiences about the experiment, which can affect outcomes.

The external validity of controlled behavioural experiments, i.e. to what extent results can be generalised beyond the experiment, is a question frequently asked (Levitt and List 2007; Falk and Heckman 2009; Gelcich et al. 2013). As a first step, researchers may want to reflect on the instructions and framing used - do they capture the situation and conditions the researcher wants to capture? Researchers could evaluate the representativeness of their 
sample. Have the results been obtained with the kind of people the researcher wants to say something about? Researchers could also ask themselves if they need to generalise the results beyond the experimental context, and if this is the case, what pieces of the overall puzzle are missing. As with all research, it is important to keep in mind that one experimental study is not a proof of anything. The positive side of using controlled experiments is that the designs can be easily replicated, especially since practically all scientific peer-review journals require experimental instructions and protocols to be reported.

\section{Resource implications}

The type of experiments presented here can be more or less costly, depending on the size of (monetary) incentives used, the number of treatments and consequently the number of participants to be paid. Other potential costs involve facilities and whether the experiment involves fieldwork or not. Moreover, some type of ethical clearance will be required but the exact requirements depend on the rules and regulations of the researcher's home institution and where the experiment will be conducted. Besides ethical clearance, experiments can be administratively burdensome for other reasons, e.g. the regulations of the researcher's home institution regarding paying the participants. Experiments need to be thoroughly planned and experimenters and assistants well trained because tight control is essential for the method (one minor mistake can ruin a whole dataset). Experiments can be pen-and-paper based or computer based, in which case some programming skills are required (Janssen, Lee, and Waring 2014). To analyse the results, statistical skills and skills for using adequate statistical software are necessary.

\section{New directions}

Most public good and common-pool resource experiments illustrate (more or less explicitly) that the social dynamics of groups are crucial for determining overall outcomes. Although we often equate social dynamics with communication, making agreements or cooperation, social dynamics also include many other aspects, e.g. how group members perceive their fellow group members, or biophysical conditions, which in turn influence communication and cooperation. Emergent social dynamics depend not only on individual and group attributes and the design and framing of the experiment but also on broader contextual factors such as the social groups the participants belong to and the broader socio-cultural and biophysical (i.e. social-ecological) contexts in which they live (Schill et al. 2019). Thus, if we want to further our understanding of the social-ecological conditions under which cooperation and sustainable resource use can be attained, controlled behavioural experiments should continue to focus on cross-cultural studies (such as those conducted by Cárdenas et al. 2017), especially systematic ones.

The controlled behavioural experiments discussed in this chapter are good for revealing behavioural outcomes in different experimental conditions, but it is more challenging for these experiments to unravel the specific motivations, drivers and mechanisms underlying behavioural outcomes. We therefore see a research frontier in combining controlled behavioural experiments with complementary methods and approaches beyond the usual post-experimental surveys. To advance understanding about the emotional drivers of decision-making, for example, insights and applications from neuroscience could be used, building on the work done in neuroeconomics (Rilling and Sanfey 2011; Glimcher and 


\section{Case study 21.1: Framed lab experiments to explore effects of potential ecological regime shifts on cooperative behaviour and sustainable resource use}

While our understanding of the drivers and impacts of regime shifts has advanced significantly, empirical research on how human behaviour relates to regime shifts and their associated uncertainties has received hardly any attention - specifically, how resource users deal with the possibility that their actions might induce these shifts (endogenously driven). This led Lindahl, Crépin and Schill (2016) to ask the following question: what is the effect of an endogenously driven ecological regime shift on human behaviour, particularly in relation to the emergence of collective action and sustainable resource use?

To answer this research question, the authors for several reasons made use of controlled behavioural experiments in the form of a framed common-pool resource game. First, pre- and post-shift social-ecological data are seldom available, which limited possibilities for case study analyses. The experimental method allowed the authors to gather observational data on individual and group behaviour and to test causal relationships. By using the experimental method, they could isolate and causally link behavioural responses to specific resource dynamics. Furthermore, they observed revealed behaviour rather than stated behaviour (which can be subjected to hypothetical biases). Finally, they could compare and contrast their insights with the vast amount of previous experimental research in the commons literature.

The authors conducted a series of framed lab experiments between 2014 and 2015 in Stockholm (Schill, Lindahl, and Crépin 2015; Lindahl, Crépin, and Schill 2016). Groups of four participants each represented fictive resource users who had common access to a renewable resource. Over a number of rounds (unknown to the participants), they made individual and anonymous decisions about how many units of the shared resource they would like to harvest, where each harvested unit was worth money (real). Participants belonging to the same group were allowed to communicate with one another throughout the game. The groups faced different resource dynamics (treatments). Some groups played a game where there was no risk of a latent regime shift (no threshold treatment). Other groups faced resource dynamics with a latent regime shift below a certain resource stock size (threshold treatment) and some groups were told that they faced a risk of a latent regime shift with a certain percentage (90\%,50\% and 10\%). The authors' main challenge with this project was to create an experimental design that was able to capture the ecological complexity while being understandable to the participants. They solved this by keeping the institutional aspects of the game as simple as possible.

In short, the results showed that cooperation was endogenous to the treatment, i.e. it depended on the resource dynamics each group faced. A latent regime shift (or when

Fehr 2013). Other interesting directions are to combine controlled behavioural experiments with interpretive approaches that seek to understand diverse contextual meanings (potential methods include in-depth interviews or focus groups, see Chapter 7) or with agent-based models (see e.g. Schill et al. 2016 for an example of this; also see Chapter 28) to unpack micro- and meso-level mechanisms. 


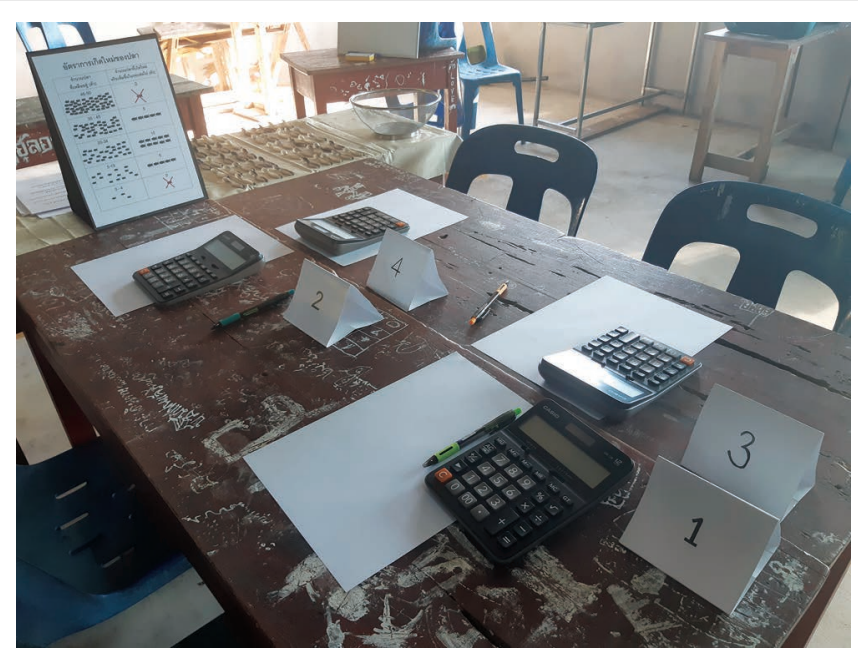

Figure 21.1 Experimental set-up for study with Thai fishers (@ Therese Lindahl)

the risk of a regime shift was high) led to more communication and cooperative agreements emerging than when there was no shift or when the risk of a latent shift was low. The authors also found that communication led to knowledge sharing and more efficient management. This implies that a latent regime shift was also associated with less overexploitation compared to a case without such a shift. The authors also found that behaviour was affected by how risk was communicated, where familiar examples (like flipping a coin) triggered more cooperative behaviour.

Our main conclusion from these experiments relates to the importance of communicating about potential regime shifts, and how this is done. The results highlight the importance of enabling arenas for knowledge sharing and communication. Field experiments with Colombian and Thai fishers using a similar (although somewhat simplified) version have also been conducted. Figure 21.1 shows the table set-up for the Thai experimental participants (fishers) at a local school in a Thai fishing village. Fish bait (shaped as fish) was used to mimic fish and fish dynamics. The dynamics were illustrated visually in a table-like format on a paper board. Preliminary results (Lindahl and Jarungrattanapong 2018; Schill and Rocha 2019) show that socio-economic conditions (community effects) and individual background variables (linked to resource dependency) influence behaviour in these games. This highlights the need for more systematic explorations of the role of contextual factors and how they interact with ecological conditions for cooperation and sustainable resource use.

Finally, an interesting development in the application of public good and common-pool resource experiments is to use them to improve understanding of key social-ecological feedbacks to motivate behavioural change or facilitate local self-governance beyond the experiment or 'field lab', into the participants' everyday life (see Meinzen-Dick et al. 2018 for an example on how 'playing games' can save water). 


\section{Key readings}

Anderies, J.M., M.A Janssen, F. Bousquet, J.C. Cárdenas, D. Castillo, M-C. Lopez, R. Robias, B. Vollan, and A. Wutich. 2011. 'The Challenge of Understanding Decisions in Experimental Studies of Common-pool Resource Governance.' Ecological Economics 70: 1571-1579.

Friedman D., and S. Sunder. 1994. Experimental Methods: A Primer for Economists. Cambridge: Cambridge University Press.

Kopelman, S., J.M. Weber, and D.M. Messick. 2002. 'Factors Influencing Cooperation in Commons Dilemmas: A Review of Experimental Psychological Research.' In The Drama of the Commons, edited by E. Ostrom, T. Dietz, N. Dolšak, P.C. Stern, S. Stonich, E.U. Weber, and The Committee on the Human Dimensions of Global Change, Division of Behavioral and Social Sciences and Education. Washington: National Academy Press.

Ostrom, E. 2006. 'The Value-added of Laboratory Experiments for the Study of Institutions and Common-pool Resources.' Journal of Economic Behavior and Organization 61(2): 149-163.

Poteete, A., M.A. Janssen, and E. Ostrom. 2009. 'Experiments in the Laboratory and the Field.' In Working Together: Collective Action, The Commons, and Multiple Methods in Practice, edited by A. Poteete, M.A. Janssen, and E. Ostrom, 229-265. Princeton: Princeton University Press.

\section{Acknowledgements}

Therese Lindahl and Caroline Schill thank the Swedish Research Council (No. 2017-05641) and the Kjell and Märta Beijer Foundation for support. Marco Janssen thanks the US National Science Foundation (no. 1658608) for support.

\section{References}

Anderies, J.M., M.A. Janssen, A. Lee, and H. Wasserman. 2013. 'Environmental Variability and Collective Action: Experimental Insights from an Irrigation Game.' Ecological Economics 93: $166-176$.

Barrett, S. 2016. 'Collective Action to Avoid Catastrophe: When Countries Succeed, When They Fail, and Why.' Global Policy 7(Supplement 1). doi:10.1111/1758-5899.12324.

Barrett, S., and A. Dannenberg. 2012. 'Climate Negotiations under Scientific Uncertainty.' Proceedings of the National Academy of Sciences 109(43): 17372-17376.

Bromley, D.W. 1992. 'The Commons, Common Property, and Environmental Policy.' Environmental and Resource Economics 2(1): 1-17.

Cárdenas, J.C. 2000. 'How do Groups Solve Local Commons Dilemmas? Lessons from Experimental Economics in the Field.' Environment, Development and Sustainability 2: 305-322.

Cárdenas, J.C., and S. Carpenter. 2009. 'Risk Attitudes and Well-being in Latin America.' Journal of Development Economics 103: 52-61.

Cárdenas, J.C., M.A. Janssen, M. Ale, R. Bastakoti, A. Bernal, J. Chalermphol, Y. Gong, H. Shin, G. Shivakoti, Y. Wang, and J.M. Anderies. 2017. 'Fragility of the Provision of Local Public Goods to Private and Collective Risks.' Proceedings of the National Academy of Sciences 114(5): 921-925.

Cárdenas, J.C., M.A. Janssen, and F. Bousquet. 2013. 'Dynamics of Rules and Resources: Three New Field Experiments on Water, Forests and Fisheries.' In Handbook on Experimental Economics and the Environment, edited by J.A. List and M.K. Price. Cheltenham: Edward Elgar.

Cárdenas, J.C., and E. Ostrom. 2004. 'What do People Bring into the Game? Experiments in the Field about Cooperation in the Commons.' Agricultural Systems 82: 307-326.

Cárdenas, J.C., J. Strandlund, and C. Willis. 2000. 'Local Environmental Control and Institutional Crowding-out.' World Development 28(10): 1719-1733.

Dawes, R.M., J. McTavish, and H. Shaklee. 1977. 'Behavior, Communication and Assumptions about Other People's Behavior in a Commons Dilemma Situation.' Journal of Personality and Social Psychology 35: 1-11.

Engel, C. 2011. 'Dictator Games: A Meta Study.' Experimental Economics 14(4): 583-610.

Falk, A., and J.J. Heckman. 2009. 'Lab Experiments are a Major Source of Knowledge in the Social Sciences.' Science 326(5952): 535-538. 
Fehr, E., and U. Fischbacher. 2002. 'Why Social Preferences Matter: The Impact of Non-selfish Motives on Competition, Cooperation and Incentives.' The Economic Journal 112(478): doi:10.1111/1468-0297.00027.

Finkbeiner E.M., F. Micheli, F., A. Saenz-Arroyo, L. Vazquez-Vera, C.A. Perafan, and J.C. Cárdenas. 2018. 'Local Response to Global Uncertainty: Insights from Experimental Economics in Smallscale Fisheries.' Global Environmental Change 48: 151-157.

Gelcich, S., R. Guzman, C. Rodriguez-Sickert, J.C. Castilla, and J.C. Cárdenas. 2013. 'Exploring External Validity of Common Pool Resource Experiments: Insights from Artisanal Benthic Fisheries in Chile.' Ecology and Society 18(3): 2.

Glimcher, P.W., and E. Fehr. 2013. 'Introduction: A Brief History of Neuroeconomics.' In Neuroeconomics: Decision Making and the Brain (2nd ed), edited by P.W. Glimcher and E. Fehr, xvii-xxviii. Cambridge: Academic Press.

Gneezy, U., A. Leibbrandt, and J.A. List. 2015. 'Ode to the Sea: Workplace Organizations and Norms of Cooperation.' The Economic Journal 126(595): 1856-1883.

Harrison, G.W., and J.A. List. 2004. 'Field Experiments.' Journal of Economic Literature 42(4): 1009-1055.

Herr, A., R. Gardner, and J.M. Walker. 1997. 'An Experimental Study of Time-independent and Time-dependent Externalities in the Commons.' Games and Economic Behavior 19(1): 77-96.

Hine, R., and D.W. Gifford. 1996. 'Individual Restraint and Group Efficiency in Commons Dilemmas: The Effects of Two Types of Environmental Uncertainty.' Journal of Applied Social Psychology 26(11): 993-1009.

Janssen, M.A., J.M. Anderies, and J.C. Cárdenas. 2011. 'Head-enders as Stationary Bandits in Asymmetric Commons: Comparing Irrigation Experiments in the Laboratory and the Field.' Ecological Economics 70: 1590-1598. 10.1016/j.ecolecon.2011.01.006.

Janssen, M.A., R. Holahan, A. Lee, and E. Ostrom. 2010. 'Lab Experiments for the Study of Social-Ecological Systems.' Science 328: 613-617.

Janssen, M.A., A. Lee, and T.M. Waring. 2014. 'Experimental Platforms for Behavioral Experiments on Social-Ecological Systems.' Ecology and Society 19(4): 20.

Janssen, M.A., T. Lindahl, and J. Murphy. 2015. 'Advancing the Understanding of Behavior in Social-Ecological Systems: Results from Lab and Field Experiments.' Ecology and Society 20(4): 34.

Johnson, N.D., and A.A. Mislin. 2011. 'Trust Game: A Meta-analysis.' Journal of Economic Psychology 32(5): 865-889. doi:10.1016/j.joep.2011.05.007.

Jorgenson, D.O., and A.S. Papciak. 1981. 'The Effects of Communication, Resource Feedback, and Identifiability on Behavior in a Simulated Commons.' Journal of Experimental Social Psychology 17(4): 373-385.

Kerr, N.L. 1989. 'Illusions of Efficacy: The Effects of Group Size on Perceived Efficacy in Social Dilemmas.' Journal of Experimental Social Psychology 25(4): 287-313.

Kopelman, S., J.M. Weber, and D.M. Messick. 2002. 'Factors Influencing Cooperation in Commons Dilemmas: A Review of Experimental Psychological Research.' In The Drama of the Commons, edited by E. Ostrom, T. Dietz, N. Dolšak, P.C. Stern, S. Stonich, E.U. Weber, and The Committee on the Human Dimensions of Global Change, Division of Behavioral and Social Sciences and Education. Washington: National Academy Press.

Levitt, S.D., and J.A. List. 2007. 'What Do Laboratory Experiments Measuring Social Preferences Reveal about the Real World?' Journal of Economic Perspectives 21(2): 153-174.

Lindahl, T., A-S. Crépin, and C. Schill. 2016. 'Potential Disasters Can Turn the Tragedy into Success.' Environmental and Resource Economics 65(3): 657-676.

Lindahl, T., and R. Jarungrattanapong. 2018. 'Avoiding Catastrophic Collapse in Small Scale Fisheries through Inefficient Cooperation: Evidence from a Framed Field Experiment.' Beijer Discussion Papers 263. Stockholm: Beijer Institute of Ecological Economics.

Lopez, M.C., J.J. Murphy, J.M. Spraggon, and J.K. Strandlund. 2012. 'Comparing the Effectiveness of Regulation and Pro-social Emotions to Enhance Cooperation: Experimental Evidence from Fishing Communities in Colombia.' Economic Inquiry 50(1): 131-142.

Meinzen-Dick, R., M.A. Janssen, S. Kandikuppa, R. Chaturvedi, K. Rao, and S. Theis. 2018. 'Playing Games to Save Water: Collective Action Games for Groundwater Management in Andhra Pradesh, India.' World Development 107: 40-53. 10.1016/j.worlddev.2018.02.006.

Moreno-Sánchez, R., and J. Maldonado. 2010. 'Evaluating the Role of Co-management in Improving Governance of Marine Protected Areas: An Experimental Approach in the Colombian Caribbean.' Ecological Economics 69: 2557-2567. 10.1016/j.ecolecon.2010.07.032. 
Ostrom, E. 1990. Governing the Commons: The Evolution of Institutions for Collective Action. Cambridge: Cambridge University Press.

Ostrom, E. 2000. 'Collective Action and the Evolution of Social Norms.' Journal of Economic Perspectives 14(3): 137-158.

Ostrom, E. 2006. 'The Value-added of Laboratory Experiments for the Study of Institutions and Common-pool Resources.' Journal of Economic Behavior and Organization 61: 149-163.

Ostrom, E., J. Walker, and R. Gardner. 1992. 'Covenants with and without a Sword: Self-governance is Possible.' American Political Science Review 86(2): 404-417.

Pereda, M., V. Capraro, and A. Sanchez. 2019. 'Group Size Effects and Critical Mass in Public Goods Games.' Scientific Reports 9: 5503.

Prediger, S., B. Vollan, and M. Frölich. 2011. 'The Impact of Culture and Ecology on Cooperation in a Common-pool Resource Experiment.' Ecological Economics 70(9): 1599-1608.

Rilling, J.K., and A.G. Sanfey. 2011. 'The Neuroscience of Social Decision-making.' Annual Review of Psychology 62: 23-48. doi:10.1146/annurev.psych.121208.131647.

Schill, C., J.M. Anderies, T. Lindahl, C. Folke, S. Polasky, J.C. Cárdenas, A-S. Crépin, M.J. Janssen, J. Norberg, and M. Schlüter. 2019. 'A More Dynamic Understanding of Human Behaviour for the Anthropocene.' Nature Sustainability 2: 1075-1082.

Schill, C., T. Lindahl, and A-S. Crépin. 2015. 'Collective Action and the Risk of Ecosystem Regime Shifts: Insights from a Laboratory Experiment.' Ecology and Society 20(1): 48.

Schill, C., and J.C. Rocha. 2019 'Uncertainty Can Help Protect Local Commons in the Face of Climate Change.' Beijer Discussion Papers 270. Stockholm: Beijer Institute of Ecological Economics.

Schill, C., N. Wijermans, M. Schlüter, and T. Lindahl. 2016. 'Cooperation Is Not Enough - Exploring Social-Ecological Micro-foundations for Sustainable Common-pool Resource Use.' PLoS ONE 11: e0157796. doi:10.1371/journal.pone.0157796.

Smith, V.L. 1976 'Experimental Economics: Induced Value Theory.' The American Economic Review 66(2): 274-279.

Velez, M.A., J.K. Strandlund, and J.J. Murphy. 2009. 'What Motivates Common Pool Resource Users? Experimental Evidence from the Field.' Journal of Economic Behavior and Organization 70(3): 485-497.

Vollan, B. 2008. 'Socio-ecological Explanations for Crowding-out Effects from Economic Field Experiments in Southern Africa.' Ecological Economics 67(4): 560-573.

Walker, J.M., and R. Gardner. 1992. 'Probabilistic Destruction of Common-pool Resources: Experimental Evidence.' The Economic Journal 102: 1149-1161. 